\title{
WITTGENSTEIN: A FILOSOFIA COMO UMA COMPOSIÇÃO POÉTICA
}

\author{
Wittgenstein: the philosophy as a poetic composition
}

Edimar Inocencio Brigido *

Resumo: Este trabalho pretende analisar em que sentido se dá a afirmação wittgensteiniana, que a filosofia só deveria ser escrita como uma composição poética. De acordo com Wittgenstein, os poetas são criadores de novas linguagens. Porém, o autor do Tractatus, em sua atividade filosófica, não procurou criar uma nova linguagem, antes, lutou com a linguagem a fim de superar os erros decorrentes do seu mau uso. A atividade filosófica desenvolvida por Wittgenstein, em seus últimos escritos, é uma atividade que se dá na linguagem de todos os dias, comum a todos os homens em suas mais variadas formas de vida. Desse modo, ao comparar a filosofia com a poesia, Wittgenstein está chamando a atenção para o seu modo de fazer filosofia. Na poesia a língua ultrapassa sua função meramente comunicativa e se torna a matéria prima para a própria obra de arte. Em outras palavras, na atividade poética o esforço do poeta incide sobre a estrutura daquilo que ele pretende expressar, sobre a melhor forma de dizer. Assim, aproximação possível entre os poetas e Wittgenstein é no que tange à matriz poética, característica do pensamento wittgensteiniano, o que nos permite questionar: seria Wittgenstein um filósofo poeta? Objetivamos, portanto, averiguar, ainda que de modo inicial, em que sentido seria lícito compreender e aproximar a filosofia com o poetar.

Palavras-chave: Filosofia. Poesia. Linguagem. Atividade. Wittgenstein.

\begin{abstract}
This paper aims to analyze in what sense the Wittgenstein's affirmation that the philosophy should be written as a poetic composition only. According to Wittgenstein, the poets are creators of new languages. Shakespeare would be a pragmatic example of this. However, the Tractatus author, in his philosophical activity, didn't attempt to create a new language but he struggled with the language in order to overcome the mistakes derived from its improper use. The philosophical activity developed by Wittgenstein, in his last writings, is an every day language activity, common to all men in their diverse form of life. Thereby, when comparing philosophy with poetry, Wittgenstein is drawing attention to his way of dealing with philosophy. It is the same model, typical of poets, in other words, an activity of composition that requires attention and patience, as a true artistic work. In poetry, the language surpasses its merely communicative function and becomes the raw material to its own work of art. That is to say that in the poetic activity, the poet's struggle concerns about the structure of what he intends to express, about the best way of speaking. Thus, the possible approach between the poet and Wittgenstein is what concerns to the poetic matrix, characteristic of the Wittgenstein's thought, which allows us to question: would Wittgenstein be a poet philosopher?

Palavras-chave: Philosophy. Poetry. Language. Activity. Wittgenstein.
\end{abstract}

* Doutorando em Filosofia na PUC/PR. Professor de Ética na UNICURITIBA. E-mail: edimarbrigido@hotmail.com

\begin{tabular}{|c|c|l|l|l|l|}
\hline intuitio & $\begin{array}{c}\text { ISSN } \\
1983-4012\end{array}$ & Porto Alegre & Vol.8 $-\mathrm{N}^{\mathrm{o}} .1$ & $\begin{array}{c}\text { Junho } \\
2015\end{array}$ & p.218-227 \\
\hline
\end{tabular}




\section{Introdução}

No ano de 1947, Wittgenstein analisou um poema que recebera de seu amigo Paul Engelmann ${ }^{1}$, o qual narra o fato ocorrido com um soldado que, ao regressar do campo de batalha, levara para sua casa um ramo de pilriteiro, plantando-o em suas terras. Anos mais tarde, já com idade avançada, o velho soldado senta-se na sombra do pilriteiro, uma árvore frondosa, que se torna uma lembrança da sua juventude, dos tempos de guerra, dos tempos que não voltam mais, dos quais a lembrança e a árvore de pilriteiro são as melhores recordações. Esse poema torna-se especial para Wittgenstein, considerando-o uma expressão perfeita do inefável: "O poema é verdadeiramente magnífico. E é assim que as coisas são: se não tentamos exprimir o que é inexprimível então nada se perde. Mas o inexprimível estará - inexprimivelmente contido naquilo que foi expresso"2. Assim é em se tratando de poesia, assim deve ser na filosofia.

Em uma passagem de Cultura e Valor ${ }^{3}$, Wittgenstein resume toda a sua atividade filosófica nas seguintes palavras: "penso ter resumido a minha atitude para com a filosofia quando disse: a filosofia deveria apenas escrever-se como um poetizar"4 . Essa afirmação se mostra reveladora, sendo possível, segundo as considerações de Nuno Crespo ${ }^{5}$, destacar ao menos três elementos fundamentais dessa afirmação wittgensteiniana ${ }^{6}$ :

Primeiro, o que Wittgenstein diz é que se trata de uma afirmação que resume sua posição filosófica e não que a sua atividade é poética. Segundo, não afirma que a sua filosofia seja poesia, mas sim que a filosofia deveria poder ser um poetar e, sabemo-lo, não o é. Terceiro, em nenhum momento Wittgenstein se refere à atividade da escrita poética como a boa imagem para descrever a sua posição ou esforços filosóficos.

1 Trata-se do poema Graf Eberhards Weissdorn, de Uhland.

2 MONK, R. Wittgenstein: o dever do gênio. Tradução de Carlos Afonso Malferrari. São Paulo: Companhia das Letras, 1990, p. 145.

3 Vermischte Bermerkungen (Cultura e Valor), reúne anotações feitas por Wittgenstein entre os anos de 1914 a 1951, tratando de questões referente a cultura de sua época, abrangendo elementos que versam sobre literatura, música, estética, história, e questões religiosas. As considerações destas notas disponibilizam uma chave de leitura fundamental para compreender o núcleo lógico, ou gramatical, da filosofia wittgensteiniana e um referencial filosófico para discutir o modelo cultural adotado pela civilização ocidental. O teor do livro revela vividamente a profundidade e seriedade do carácter de Wittgenstein e a sua busca pela verdade. Torna-se relevante destacar que, nesta pesquisa, essa obra serve apenas de esboço na qual é possível ler a filosofia wittgensteiniana a partir de uma atitude poética.

${ }^{4}$ WITTGENSTEIN. Cultura e Valor. Tradução de Jorge Mendes. Lisboa: Edições 70, 2000, pp. 43-44.

5 CRESPO, N. Wittgenstein e a estética. Lisboa: Assírio e Alvim, 2011. p. 354.

6 Alguns comentadores, como, por exemplo G. H. von Wright, P. Winch, G. Granel, entre outros, defendem que a afirmação citada em Cultura e Valor sugere que a escrita filosófica deva seguir o modelo da escrita poética, ou seja, asseguram que a filosofia deveria ser escrita como se escreve um poema. Porém, nossa análise leva em consideração o termo alemão Dichten (poetar), o qual sugere não um gênero ou um estilo de escrita, mas uma atividade que está relacionada com o sentido grego de poiesis.

\begin{tabular}{|c|c|c|c|c|c|}
\hline intuitio & $\begin{array}{c}\text { ISSN } \\
1983-4012\end{array}$ & Porto Alegre & Vol.8 $-\mathrm{N}^{\circ} .1$ & $\begin{array}{c}\text { Junho } \\
2015\end{array}$ & p.218-227 \\
\hline
\end{tabular}


Wittgenstein acreditava que os poetas criavam linguagens, dizia que Shakespeare era "um criador de uma nova linguagem" ${ }^{\text {, }}$ o que não se aplica aos filósofos. Em sua filosofia não procurou criar uma nova linguagem; antes, lutou com a linguagem a fim de superar os erros decorrentes do seu mau uso. No máximo, o que Wittgenstein fez foi criar novos símiles, imaginar novas formas de vida, utilizar conceitos fictícios, assim como a poesia faz e utiliza, com o objetivo de tornar a filosofia uma atividade terapêutica libertadora. Moreno $^{8}$ assegura que "as metáforas e, mais amplamente, as ligações analógicas terão um papel importante na reflexão de Wittgenstein após o Tractatus”.

$\mathrm{Na}$ poesia, segundo as considerações de Wittgenstein, cada expressão precisa ser colocada cuidadosamente e artisticamente no local adequado, é isso o que garante a beleza e a integridade do poema. Da mesma forma, considera que em filosofia uma boa metáfora ou uma expressão correta pode ser mais importante do que a formulação de uma hipótese ou de uma teoria. Uma boa analogia gera como consequência a satisfação, enquanto que uma teoria ou hipótese precisa passar pela verificação: "E se a metáfora se revela boa por sua capacidade de iluminar o emprego da linguagem, a claridade que reporta pode ser um fim em si mesmo"”. Além do mais, uma teoria nunca é definitiva, já uma metáfora subsiste no tempo, gerando um efeito libertador.

A atividade filosófica desenvolvida por Wittgenstein, em seus últimos escritos, é uma atividade que se dá na linguagem de todos os dias, em sua forma ordinária, comum a todos os homens em suas mais variadas formas de vida, conforme adverte nas Investigações:

Quando falo da linguagem (palavra, frase, etc.) devo falar a linguagem do cotidiano. Seria essa linguagem talvez muito grosseira, material, para aquilo que queremos dizer? E como se forma então uma outra? - E como é espantoso que possamos fazer alguma coisa com a nossa! O fato de que, nas minhas elucidações referentes à linguagem, já sou obrigado a empregar a linguagem inteira (e não uma preparatória, provisória), já mostra que posso apenas produzir algo exterior sobre a linguagem ${ }^{10}$.

É na linguagem de todos os dias, do cotidiano que Wittgenstein desenvolve sua tarefa. Desse modo, ao comparar a filosofia com a poesia, com o Dichten, o poetar, Wittgenstein está chamando a atenção para o seu modo de fazer filosofia. Trata-se do mesmo modelo característico dos poetas, ou seja, uma atividade de composição, que exige atenção e calma, assim como uma verdadeira obra artística. Na poesia, a língua ultrapassa sua função meramente comunicativa e se torna a matéria prima para a própria obra de arte. Em outras palavras, na atividade poética o esforço do poeta incide sobre a estrutura daquilo que ele pretende expressar, sobre a melhor forma de dizer. Na poesia se evidenciam as potencialidades da

\footnotetext{
${ }^{7}$ WITTGENSTEIN. Cultura e Valor. Tradução de Jorge Mendes. Lisboa: Edições 70, 2000, p. 123.

${ }^{8}$ MORENO, A. Wittgenstein os labirintos da linguagem. São Paulo: Moderna, 2000, p. 61.

${ }^{9}$ ARENAS, L. A lo que el arte debe apuntar: el Tractatus y el ideal de la obra de arte en el joven Wittgenstein. In: MARRADES, J. Wittgenstein Arte e Filosofía. Madrid: Plaza y Valdes editores, 2013, pp. 150-151.

${ }^{10}$ WITTGENSTEIN. Investigações Filosóficas. Petrópolis: Vozes, 1994, p. 73.
}

\begin{tabular}{|c|c|l|l|l|l|}
\hline intuitio & $\begin{array}{c}\text { ISSN } \\
1983-4012\end{array}$ & Porto Alegre & Vol.8 $-\mathrm{N}^{\mathrm{o}} .1$ & $\begin{array}{c}\text { Junho } \\
2015\end{array}$ & p.218-227 \\
\hline
\end{tabular}


linguagem, como, por exemplo, a metáfora, a conotação, a sonoridade, o ritmo, a analogia, a figura de linguagem, etc., em resumo, a maneira peculiar, nova, criativa de expressar, o que também se aplica ao modo de fazer filosofia, o que permite concluir que "Wittgenstein não é o filósofo-poeta, nem sua filosofia poesia"11. A aproximação possível entre o poeta e Wittgenstein é no que tange à matriz poética, característica do pensamento wittgensteiniano, o que permite concluir que a correta leitura da filosofia desse pensador se dá a partir de uma atitude poética.

É possível identificar nos escritos de Wittgenstein, como por exemplo nos aforismos ${ }^{12}$, uma característica da escrita empregada no Tractatus, uma disposição, uma intensidade poética, o que não pode ser confundido como uma realização poética, com a atividade de escrever poemas, porque escrever poemas consiste em criar uma nova linguagem, o que parece ser inexistente na longa atividade desenvolvida por ele.

Wittgenstein não escreve poesia, seus aforismos não são versos de uma prosa poética, embora a proximidade entre seus escritos e os do poeta seja evidente. O que Wittgenstein produz são observações; trata-se de pura filosofia, na qual o que está em causa, assim como no caso da poesia, é a luta com a linguagem, é o desejo de encontrar a palavra correta, a palavra que liberta, que alivia do desconforto, que identifica o lugar onde o "sapato lhe aperta":

Um belo poema ou uma obra musical produzem essa libertação que é um tipo de satisfação positiva não pelo que dizem - afinal não dizem nada - mas porque o poema e a música mostram aspectos da linguagem que são valiosos e importantes para aqueles que se aproximam delas com a capacidade de maravilhar-se ${ }^{13}$.

A solução dos problemas de filosofia não depende da explicação de regras objetivas, mas do mínimo de imaginação metafórica capaz de reconhecer o gesto e maravilhar-se: "se um tema, uma frase, significa subitamente algo para ti, não tens de ser capaz de o explicar. Apenas este gesto se tornou acessível para ti’"14. Só assim os problemas podem ser elucidados em suas mais variadas formas de vida: "Esse mínimo imaginativo é uma condição da experiência filosófica no sentido em que são certas

11 CRESPO, N. Wittgenstein e a estética. Lisboa: Assírio e Alvim, 2011. p. 355.

12 O aforismo, caracterizado pela prosa, foi o estilo de escrita adotado por Wittgenstein em muitos dos seus textos, em oposição ao modelo adotado ao longo da tradição. Fica evidente que esse modelo é, antes de tudo, uma disposição semelhante à disposição do poeta, mas não poesia em si. Não pretendemos destacar elementos estruturais, porém, é importante sublinhar que a aproximação entre a prosa e a poesia é legítima, sendo defendida por muitos especialistas: "A poesia e a prosa não são duas artes literárias distintas, mas antes uma mesma e única arte com um único e mesmo objetivo: revelar a experiência, refletida na representação linguística. A única diferença é na verdade puramente processual, no sentido em que a construção do objetivo literário é realizado no romance e na narrativa através de um processo de decomposição e por isso de análise, enquanto que na poesia esta construção é feita à causa de um processo de condensação e por isso de síntese e, nestas circunstâncias, o conto é assim uma forma de poesia" (LOURENÇO, 2002, p. 14-15).

${ }^{13}$ MARRADES, J. Wittgenstein arte y filosofía. Madrid: Plaza y Valdes editores, 2013, p. 151.

${ }^{14}$ WITTGENSTEIN. Fichas (Zettel). Lisboa: Edições 70, 1967, p. 46.

\begin{tabular}{|c|c|c|c|c|r|}
\hline intuitio & $\begin{array}{c}\text { ISSN } \\
1983-4012\end{array}$ & Porto Alegre & Vol.8 $-\mathrm{N}^{\mathrm{o}} .1$ & $\begin{array}{c}\text { Junho } \\
2015\end{array}$ & p.218-227 \\
\hline
\end{tabular}


comparações com os símiles inventados e compostos pelo filósofo que permitem avaliar a tensão expressa num problema filosófico" $"$.

A progressiva passagem do Tractatus para as Investigações ${ }^{16}$ evidencia que "o vínculo entre uma palavra e seu significado deve ser encontrado não na teoria, mas na prática, no uso da palavra" ${ }^{\text {"17 }}$. E o novo paradigma poético tem a função de corroborar e enfatizar a índole corrente, fluente e adaptável que caracteriza a própria linguagem e a opõe ao antigo modelo lógico, eterno e imutável que caracteriza o Tractatus. Deste modo, faz-se importante ressaltar que o objetivo primordial desta pesquisa consiste em, de forma inicial, introduzir a discussão em torno da possibilidade de compreender a filosofia como uma composição poética, o que resulta na necessidade posterior de um aprofundamento por parte do leitor, onde outras bibliografias poderão e deverão ser consultadas.

\section{A LEITURA DE UM POEMA É UMA AÇÃO}

A leitura de um poema é uma ação, ou até mesmo um jogo, que acarreta uma variada gama de peripécias não só naquele que se dispõe a lê-lo, mas também naqueles que estão próximos e acompanham essa leitura e observam que a linguagem ressoa diferente do normal e acontecem coisas diferentes das que acontecem quando se lê ou se observa a leitura de um livro didático ou de um manual de informações técnicas, proveniente de um equipamento qualquer. A questão pode ser mais bem compreendida a partir de um exemplo utilizado por Wittgenstein:

Pense no caso seguinte: pessoas, ou outros seres, seriam utilizados por nós como máquinas de leitura. São treinados para essa finalidade. $\mathrm{O}$ treinador diz que alguns já podem ler, e que outros ainda não. Tome o caso de um aluno que até agora não tomara parte no treinamento: se lhe mostrarmos uma palavra escrita, ele poderá às vezes proferir sons quaisquer, e aqui e ali acontecerá então 'por acaso' de serem mais ou menos os certos. Um terceiro ouve esse aluno em tal caso e diz: "Ele lê". Mas o professor diz: "Não, ele não lê; foi apenas um acaso". - Mas suponhamos que esse aluno, ao lhe serem mostradas mais palavras, reaja a elas sempre corretamente. Após algum tempo, o professor diz: "Agora ele sabe ler!" - Mas o que ocorreu com aquela primeira palavra? O professor deve dizer: "enganei-me, ele a leu realmente" - ou: "Ele começou a ler realmente apenas mais tarde"? - Quando começou a ler? Qual é a primeira palavra que ele leu? Esta questão não tem sentido aqui. [...] Se empregarmos, ao contrario, "ler" para uma certa vivência da

\footnotetext{
${ }^{15}$ CRESPO, N. Wittgenstein e a estética. Lisboa: Assírio e Alvim, 2011. p. 361.

${ }^{16}$ Nosso objetivo não consiste em comparar os dois momentos da atividade filosófica desenvolvida pelo autor, antes porem, nossa tarefa assenta-se sobre a necessidade de analisar a sua relação com a filosofia, sem defender uma possível ruptura ou continuidade, como é comum ocorrer entre seus comentadores.

${ }^{17}$ MONK, R. Wittgenstein: o dever do gênio. Tradução de Carlos Afonso Malferrari. São Paulo: Companhia das Letras, 1990, p. 280.
}

\begin{tabular}{|c|c|c|c|c|c|}
\hline intuitio & $\begin{array}{c}\text { ISSN } \\
1983-4012\end{array}$ & Porto Alegre & Vol.8 $-\mathrm{N}^{\mathrm{o}} .1$ & $\begin{array}{c}\text { Junho } \\
2015\end{array}$ & p.218-227 \\
\hline
\end{tabular}


passagem do signo ao som falado, então há certamente sentido em falar de uma primeira palavra que ele realmente leu. Ele pode dizer, então, por exemplo: "Com essa palavra, tive pela primeira vez o sentimento: 'agora eu leio"'. Mas no caso, diferente do anterior, de uma máquina de leitura que traduz signos para sons, como o faz uma pianola, poder-se-ia dizer: "A máquina leu somente depois que isto e aquilo aconteceu com ela: depois que tais e tais partes foram ligadas por fios metálicos; o primeiro signo que ela leu foi..." Mas no caso da máquina viva de leitura, "ler" significava: reagir de tal ou tal modo a signos escritos. Este conceito era portanto completamente independente do conceito de um mecanismo psíquico, ou outro. - $\mathrm{O}$ professor também não pode aqui dizer do aluno: "Talvez ele já leu essa palavra". Pois não há nenhuma dúvida sobre o que ele fez. A modificação que se operou quando o aluno começou a ler era uma modificação do seu comportamento; e falar de uma "primeira palavra no novo estado" não tem nenhum sentido aqui ${ }^{18}$.

A variedade de reações que ocorrem e se observam na leitura de um poema se manifesta no gesto, no rosto, nas mudanças de voz, na mudança de comportamento que se faz durante ou após uma leitura, ou seja, numa mudança de aspecto, que só pode ser compreendida por aqueles que partilham da mesma forma de vida daquele que lê o poema. Uma leitura que se opõe à leitura informativa, na qual não é possível destacar quaisquer elementos expressivos, onde os sentimentos não estão aparentes, como é o caso de uma máquina de leitura, a qual apenas reproduz o que está escrito, mas não expressa nada além disso.

Ray Monk ${ }^{19}$ destaca que "notar aspectos e compreender a música, a poesia, a pintura e o humor são manifestações que pertencem a uma cultura, a uma forma de vida, e só nela podem subsistir”. Fazer parte da mesma cultura é um fator determinante para que o poema tenha sentido, caso contrário, nas palavras de Wittgenstein ${ }^{20}$ :

Que acontece quando as pessoas não têm o mesmo sentido de humor? Não regem umas às outras convenientemente. É como se entre certos homens existisse o costume de um atirar a outro uma bola, que deve ser por este agarrada e atirada de volta; mas alguns, em vez de a atirarem de volta, põem-na nos seus bolsos.

As imagens decorrentes de um poema não são as suas representações, no sentido em que surgem devido à isonomia lógico-formal entre a palavra que se pronuncia e a imagem que se vê surgir, mas são

\footnotetext{
${ }^{18}$ WITTGENSTEIN. Investigações Filosóficas. Petrópolis: Vozes, 1994, pp. 90-91.

${ }^{19}$ MONK, R. Wittgenstein: o dever do gênio. Tradução de Carlos Afonso Malferrari. São Paulo: Companhia das Letras, 1990, p. 468.

${ }^{20}$ WITTGENSTEIN. Cultura e Valor. Tradução de Jorge Mendes. Lisboa: Edições 70, 2000, p. 121.
}

\begin{tabular}{|c|c|l|l|l|l|}
\hline intuitio & $\begin{array}{c}\text { ISSN } \\
1983-4012\end{array}$ & Porto Alegre & Vol.8 $-\mathrm{N}^{\mathrm{o}} .1$ & $\begin{array}{c}\text { Junho } \\
2015\end{array}$ & p.218-227 \\
\hline
\end{tabular}


um excesso poético relativamente à linguagem, ao verso, à frase, à palavra, que só podem ser assimiladas dentro de um jogo de linguagem específico. Segundo $\mathrm{Crespo}^{21}$, o caráter de excesso

provém de se tratar de uma leitura que tem como condição não a indiferença mas uma ligação sentimental daquele que lê aquilo que está a ler: a leitura do poema exprime, por oposição à leitura de uma informação, uma satisfação relativa com o compreender de um certo modo o que se lê. E é através do conjunto destes acontecimentos expressivos e sentimentais que o significado particular de uma palavra acontece.

É importante notar que a condição para ser expresso o significado particular de uma palavra ou o sentido de um texto qualquer é a necessidade de que a leitura seja adequada, o que Wittgenstein ${ }^{22}$ chama de leitura expressiva:

Se, ao ler expressivamente, pronuncio esta palavra, então ela fica repleta do seu significado. - "Como é que isso pode ser, se o significado de uma palavra é o seu uso?" Bem, a minha expressão queria ser figurativa. Mas não é como se eu tivesse escolhido a imagem, mas ela impôs-se. - Mas a aplicação figurativa da palavra não pode entrar em conflito com a sua aplicação original ${ }^{23}$.

Na leitura expressiva é a maneira como se lê que confere significado à palavra ou ao verso, como no caso do poema, o qual não é determinado por um sistema de regras, mas surge de modo inesperado num determinado uso que se faz. Desse modo, a leitura expressiva é um uso que se faz da linguagem, em que a experiência do leitor é trazida à tona e torna-se pública, sendo compartilhada e assimilada pelos demais.

\section{AS EXIGÊNCIAS PARA LER WITTGENSTEIN E PARA LER UM POEMA}

A leitura expressiva, tanto no que diz respeito à leitura de Wittgenstein, quanto à leitura de um poema, implica algumas mudanças: mudança na forma de ver; mudança na forma de pensar e, consequentemente, uma mudança de comportamento. Somente com um novo olhar, pensando de maneira diferente é que, possivelmente, a leitura venha a atingir o seu objetivo. Foi essa a advertência que Wittgenstein já havia alertado no Prefácio do Tractatus: "este livro talvez seja entendido apenas por quem já tenha alguma vez pensado por si próprio o que nele vem expresso - ou, pelo menos, algo semelhante. não é, pois, um manual"24.

${ }^{21}$ CRESPO, N. Wittgenstein e a estética. Lisboa: Assírio e Alvim, 2011. p. 366.

${ }^{22}$ WITTGENSTEIN. Investigações Filosóficas. Petrópolis: Vozes, 1994, pp. 91.

${ }^{23}$ Esta citação se trata de uma releitura nossa do $\$ 158$ das Investigações, não sendo, portanto, uma tradução literal conforme o texto de Wittgenstein.

${ }^{24}$ WITTGENSTEIN. Tractatus Lógico-Philosophicus. São Paulo: USP. 2010, p. 131.

\begin{tabular}{|c|c|c|c|c|c|}
\hline intuitio & $\begin{array}{c}\text { ISSN } \\
1983-4012\end{array}$ & Porto Alegre & Vol.8 $-\mathrm{N}^{\circ} .1$ & $\begin{array}{c}\text { Junho } \\
2015\end{array}$ & p.218-227 \\
\hline
\end{tabular}


Dois elementos são igualmente significativos nessa citação: o primeiro é um convite a pensar de modo novo, ou semelhante ao que está sendo tratado na obra. Para isso se faz necessário conhecer as "regras", os jogos de linguagem e as formas de vida a partir dos quais o texto foi redigido. Trata-se de um pré-requisito para aqueles que desejam se aventurar nessa leitura e retirar dela algum proveito. A segunda é uma advertência: este livro "não é, pois, um manual", ou seja, não pode ser lido como se lê um manual ou um livro didático. A leitura de um poema, e incluam-se também os textos de Wittgenstein, só podem ser corretamente compreendidos quando o leitor o faz de maneira adequada, como uma leitura expressiva, respeitando as pausas dadas pelo escritor, os símiles, as idas e vindas. É necessário encontrar o "tom" correto no qual a obra foi redigida.

As palavras e os seus significados são como imagens e correspondentes modos de ver (aspectos). Wittgenstein sublinha a importância do fato que os significados e os aspectos podem ser experimentados: não é o nosso caminho habitual, mas em certos contextos - sobretudo se se está a lidar com palavras ou imagens ambíguas - expressamos a nossa compreensão de coisas linguísticas ou visuais ao clarificar que significado ou aspecto, entre muitos outros possíveis, experimentamos. Em tais casos a compreensão pode implicar saborear um tom específico, aroma ou faceta do objeto em questão e a atividade de saborear algo, bem como o resultado dessa ação, podem ser expressos nos modos típicos que pertencem a um limitado repertório de modos de mostrar o que se sentiu ${ }^{25}$.

O resultado desta atividade é uma transformação no comportamento habitual daquele que saboreou a leitura no tom certo, daquele que compreendeu o "espírito" a partir do qual a obra fora escrita. Este se torna, então, capaz de comunicar aquela experiência adquirida e, ao fazê-lo, torna exprimível aquele que outrora pertencia ao inexprimível.

Em suma, dizer que a filosofia deveria ser poesia corresponde a dizer que para compreender a atividade filosófica, desenvolvida ao longo da vida de Wittgenstein, "implica operações, métodos e inovações, que normalmente são o modo de ser da poesia"26, o que nem sempre fora bem visto pela tradição filosófica. Tanto a poesia quanto os escritos wittgensteinianos exigem um modo de composição e uma forma específica de leitura ${ }^{27}$. Trata-se, portanto, de uma condição sem a qual se está comprometendo a devida compreensão da obra.

${ }^{25}$ SCHULTE, J. The Life of the Sign. Wittgenstein on Reading a Poem. In: The Literary Wittgenstein. Ed by John Gibson and Wolfgand Huemer, Routledge, London and New York, 2004, p. 153.

${ }^{26}$ CRESPO, N. Wittgenstein e a estética. Lisboa: Assírio e Alvim, 2011. p. 372.

${ }^{27} \mathrm{Um}$ elemento que pode ser utilizado como exemplo é a forma de escrita empregada por ele. Wittgenstein não adota as formas discursivas tradicionais, submetido às exigências de clareza e de racionalidade dos conceitos empregados, abre mão de aspectos como definição de conceitos, síntese ou confronto com outros pontos de vista. Para desespero de muitos, se não da grande maioria, Wittgenstein elege o aforismo como sua modalidade de expressão escrita, na qual se destaca a brevidade aliada ao ritmo; pequenos aforismos apresentados em tom oracular, que se aceitam ou se rejeitam, mas que não convidam à discussão. Para ele, o importante era comunicar o resultado de seus esforços cognitivos, sem preocupar-se em revelar os caminhos percorridos ou as dificuldades encontradas.

\begin{tabular}{|c|c|l|l|l|l|}
\hline intuitio & $\begin{array}{c}\text { ISSN } \\
1983-4012\end{array}$ & Porto Alegre & Vol.8 $-\mathrm{N}^{\mathrm{o}} .1$ & $\begin{array}{c}\text { Junho } \\
2015\end{array}$ & p.218-227 \\
\hline
\end{tabular}


A filosofia só deveria ser lida como se lê um poema, respeitando suas particularidades, e, assim como o poema, tomar um problema filosófico é ter à frente uma experiência de prazer e de alívio. É assim com o Tractatus, cujo objetivo "teria alcançado se desse prazer a alguém que o lesse e entendesse"28, é assim nas Investigações, cujo prazer surge para aquele que encontra o caminho de volta para casa. Tudo isso pode ser resumido na ação do poetar, no modo como a poesia se apresenta e, sem pretensão alguma, comunica aquilo que de mais importante precisa ser comunicado, ou seja, o mais elevado. Isso não torna o filósofo um poeta, mas os coloca em interação por meio da linguagem.

\section{REFERÊNCIAS}

ARENAS, L. A lo que el arte debe apuntar: el Tractatus y el ideal de la obra de arte en el joven Wittgenstein. In: MARRADES, J. Wittgenstein Arte e Filosofía. Madrid: Plaza y Valdes editores, 2013

BOUVERESSE, J. La parole malheureuse: de l'alchimie linguistique a la grammaire philosophique. Paris: Les èditions de minuit, 1971.

BOUVERESSE, J. Wittgenstein: la modernidade, el progreso, y la decadencia. México: Universidad Nacional Autónoma de México, 2010.

CARROLL, N. Filosofia da Arte. Lisboa: Edições Texto \& Grafia, 2010.

CRESPO, N. Wittgenstein e a estética. Lisboa: Assírio e Alvim, 2011.

DIFFEY, T. Wittgenstein, Anti-essentialism and the Definition of Art. In: Peter Lewis (Ed.), Wittgenstein, Aesthetics and Philosophy, Aldershot, Royaume-Uni, Ashgate, coll. "Wittgensteinian studies", 2004.

FANN, K.T. El concepto de filosofia en Wittgenstein. Madrid: Tecnos, 1992.

FAVRHOLDT, D. Na interpretation and critique of Wittgenstein's Tractatus. Copenhagen: Munskgaard, 1967.

HINTIKKA, M.; HINTIKKA, J. Uma investigação sobre Wittgenstein. Campinas: Papirus, 1994.

HUISMAN, D. A Estética. Lisboa: Edições 70, 1984.

LEAVIS, F. The Two Cultures?: The Significance of C. P. Snow. London: Cambridge University Press, 1972.

LOURENÇO, M. S. Um templo no ouvido. In: Os Degraus do Parnaso. Lisboa: Assírio e Alvin, 2002.

MANDELBAUM, M. Family Resemblances and Generalizations concerning the Arts. American Philosophical Quarterly 2, 1965.

MARRADES, J. Wittgenstein arte y filosofía. Madrid: Plaza y Valdes editores, 2013.

MONK, R. Wittgenstein: o dever do gênio. Tradução de Carlos Afonso Malferrari. São Paulo: Companhia das Letras, 1990.

MORENO, A. Wittgenstein os labirintos da linguagem. São Paulo: Moderna, 2000.

RAMSEY, F. Critical Notice. Mind, 32, pp. 465-478, 1923.

SCHMITZ, F. Wittgenstein. Tradução de José Oscar de Almeida Marques. São Paulo: Figuras do saber, 2004.

SCHULTE, J. The Life of the Sign. Wittgenstein on Reading a Poem. In: The Literary Wittgenstein. Ed by John Gibson and Wolfgand Huemer, Routledge, London and New York, 2004, pp. 146-164).

SOMAVILLA, I. Las dimensiones del asombro em la filosofia de Wittgenstein. In: MARRADES, J. Wittgenstein Arte e Filosofía. Madrid: Plaza y Valdes editores, 2013

WALLNER, F. A obra de Wittgenstein como unidade. São Paulo: Tempo Brasileiro, 1997.

WEITZ, M. The Journal of Aesthetics and Art Criticism. Nova Iorque: XV, 1956.

WITTGENSTEIN, L. Anotações sobre as cores. Lisboa: Edições 70, 1977.

. Cadernos (Notebooks): 1914-1916. Biblioteca de Filosofia Contemporânea. Lisboa: Edições 70.

Edição Bilingue, 2000.

. Carnets 1914-1916. France: Gallimard, 1961.

${ }^{28}$ WITTGENSTEIN. Tractatus Lógico-Philosophicus. São Paulo: USP. 2010, p. 131.

\begin{tabular}{|c|c|c|c|c|c|}
\hline intuitio & $\begin{array}{c}\text { ISSN } \\
1983-4012\end{array}$ & Porto Alegre & Vol.8 $-\mathrm{N}^{\mathrm{o}} .1$ & $\begin{array}{c}\text { Junho } \\
2015\end{array}$ & p.218-227 \\
\hline
\end{tabular}


Conferência sobre ética: In. DALL'AGNOL, D. Ética e Linguagem: uma introdução ao Tractatus de Wittgenstein. $3^{\mathrm{a}}$ ed. Florianópolis: Ed. Da UFSC, 2005.

Cultura e Valor. Lisboa: Edições 70, 2000.

Estética, psicologia e religião. São Paulo: Cultrix, 1966.

Fichas (Zettel). Lisboa: Edições 70, 1967.

. Investigações Filosóficas. Petrópolis: Vozes, 1994.

Tractatus Lógico-Philosophicus. São Paulo: USP. 2010.

Recebido em: 16/09/2014

Aprovado para publicação em: 23/04/2015 